\title{
Proyectos de Título
}

\section{Graduation Projects}

\author{
A r q. Pil ar Barba B. \\ Directora Escuela de Arquitectura, \\ Facultad de Arquitectura y Urbanismo, Universidad de chile
}

\section{$<$ Resumen>}

En las siguientes páginas se muestra una selección de proyectos de Título de nuestra Escuela que nos permiten una reflexión acerca de la misión de ésta, sus resultados y desafíos futuros.

A 157 años de la creación del "Curso de Arquitectura" por Claude François Brunet de Baines, la Escuela de Arquitectura de la Universidad de Chile, mantiene su compromiso con la formación de "arquitectos que el país necesita", con una vocación social, solvencia técnica, respeto por el patrimonio y la calidad de vida en la ciudad; valores expresados en un diseño adecuado, consciente del contexto cultural mundial y local.

\section{Resultados}

Esta promoción ha abordado temas de interés nacional. Los proyectos demuestran distintas escalas de dominio: desde lo territorial, lo urbano, hasta el contexto inmediato y el espacio interior. Se han abordado, desde el punto de vista programático, temas de interés nacional como espacios para instalaciones industriales para el procesamiento de la basura, museos, espacios para la cultura, etcétera.

Este año también se podría caracterizar por una preocupación hacia los aspectos metodológicos que permiten al arquitecto, por un lado, interactuar con la complejidad de la realidad y por otro, ampliar nuestro lenguaje a otros campos disciplinares.

\section{Desafíos}

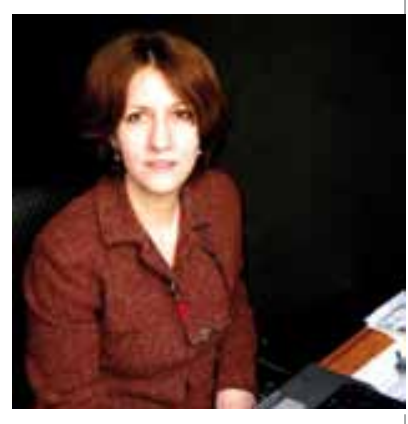

El proyecto de título y el examen de grado son la última instancia regular de formación de un arquitecto. Sin embargo, la rapidez de los cambios en el medio laboral, las nuevas condiciones políticas, económicos, sociales, hacen hoy más necesaria y urgente que la relación de la Escuela y sus egresados sea una a largo plazo. Le corresponde a la Universidad ofrecer el espacio para la actualización de conocimientos y el encuentro con pares y especialistas en cursos, seminarios, postítulos y posgrados. Pero esto también esperando que los egresados sean agentes que pongan en contacto a la academia con la realidad del ejercicio profesional. Este último aspecto es hoy relevante para la reformulación del perfil del arquitecto dentro de la Reforma de Pregrado en curso en nuestra Universidad.

La correcta formulación del Programa debiera volver a ser una prerrogativa del arquitecto, como también la concepción del espacio público, recuperando el arquitecto un rol protagónico en los equipos de trabajo multidisciplinario. Para ello, los nuevos arquitectos (y también los mayores) no deben abandonar su capacidad de investigar, de mantenerse al día en los diferentes enfoques y discursos que atraviesan lo urbano, lo técnico, lo social y lo económico. Hoy más que nunca, cabe al arquitecto ejercer esa capacidad para la "visión de conjunto" que se desarrolla tal vez inadvertidamente en su formación profesional y que, sin embargo, más que nunca luce cuando éste se decide a emplearla. Por ello, desde el punto de vista proyectual, los arquitectos de la Universidad de Chile, no debemos olvidar nuestra tradición técnica, haciendo de ésta una característica que nos distinga y dote a nuestras obras e intervenciones de una calidad y pertinencia que nos enorgullezca.

Desde el punto de vista social, el arquitecto de la Universidad de Chile debe recuperar su rol en la definición de políticas públicas -tanto desde el ejercicio público como el privado- en campos tan importantes como la vivienda, el barrio, el transporte y la planificación urbana, tan dañada por los criterios del mero mercado y la oportunidad de lucro. Los nuevos arquitectos de la Universidad de Chile están llamados hoy, igual que antes, a desempeñarse a lo largo de nuestro país integrando las necesidades de los ciudadanos, los contextos físicos, sociales y culturales de cada región, contribuyendo a disminuir la inequidad y mejorar la calidad de vida de los chilenos. 
Planta de Reciclaje de Residuos Sólidos Domiciliarios mediante incineración / Santiago

Andrés Wong B. / Profesor guía: Eduardo Lyon R.

[1] Planta del tercer piso,

[2-4] Vistas de la maqueta. I

[5] Elevación sur. / [6] Elevación norte. /

[7] Corte longitudinal. /

[8] Corte transversal.

[9] Vistas axonométricas.

En el proceso de modernización de las ciudades el rol del arquitecto es fundamental, ya que en estos procesos de desarrollo, las ciudades sufren grandes transformaciones a niveles morfológicos y de organización; es aquí donde el arquitecto tiene una participación directa en la toma de decisiones del "hacer ciudad".

En la actualidad se habla mucho del calentamiento global, los problemas de contaminación que generan las ciudades y el agotamiento de los recursos naturales. Ante esto la disciplina de la arquitectura debería estar consciente tanto en su aprendizaje como en su labor activa. Ésta debería tener respuestas o tipo de soluciones para poder proponer una disciplina capaz de absorber este tipo de problemáticas. Al parecer es capital para el futuro desarrollo de la arquitectura, tomar en cuenta estos conceptos a objeto de genera una discusión, lo que finalmente tendrá que dar resultados prácticos para poder continuar con un mejor desarrollo de la arquitectura.

Se ha basado el desarrollo del proyecto de título, partiendo en la búsqueda de una problemática relacionada con el medioambiente, en específico la contaminación que genera la basura, y los problemas que ésta trae consigo. El análisis de esta problemática se emplaza desde la mirada del gobierno y los instrumentos mediante los cuales la controla (CONAMA, SESMA, EIA, instrumentos Municipales). Se revisan los sistemas de tratamiento y las soluciones que existen hoy en día, y cuales de éstas son los que se llevan a cabo en Chile.

Luego de revisar alternativas al problema, se escoge la del reciclaje como la mejor manera de solucionar el problema de la basura, se revisan los tipos que existen y cuales de éstos son implementados actualmente. Después de un análisis se elige la incineración como la solución más óptima, y la que mejor ataca el problema de raíz. Basándose en la investigación y en la toma de decisiones en como afrontar el problema, se realiza un anteproyecto de arquitectura.

El anteproyecto "Planta de Reciclaje de Residuos Sólidos Domiciliarios mediante Incineración", se realiza desde la base de una profunda investigación, de la tecnología y los procesos que ésta requiere, y el entendimiento de los desarrollos tecnológicos que juegan el papel principal en el diseño de la arquitectura del proyecto.
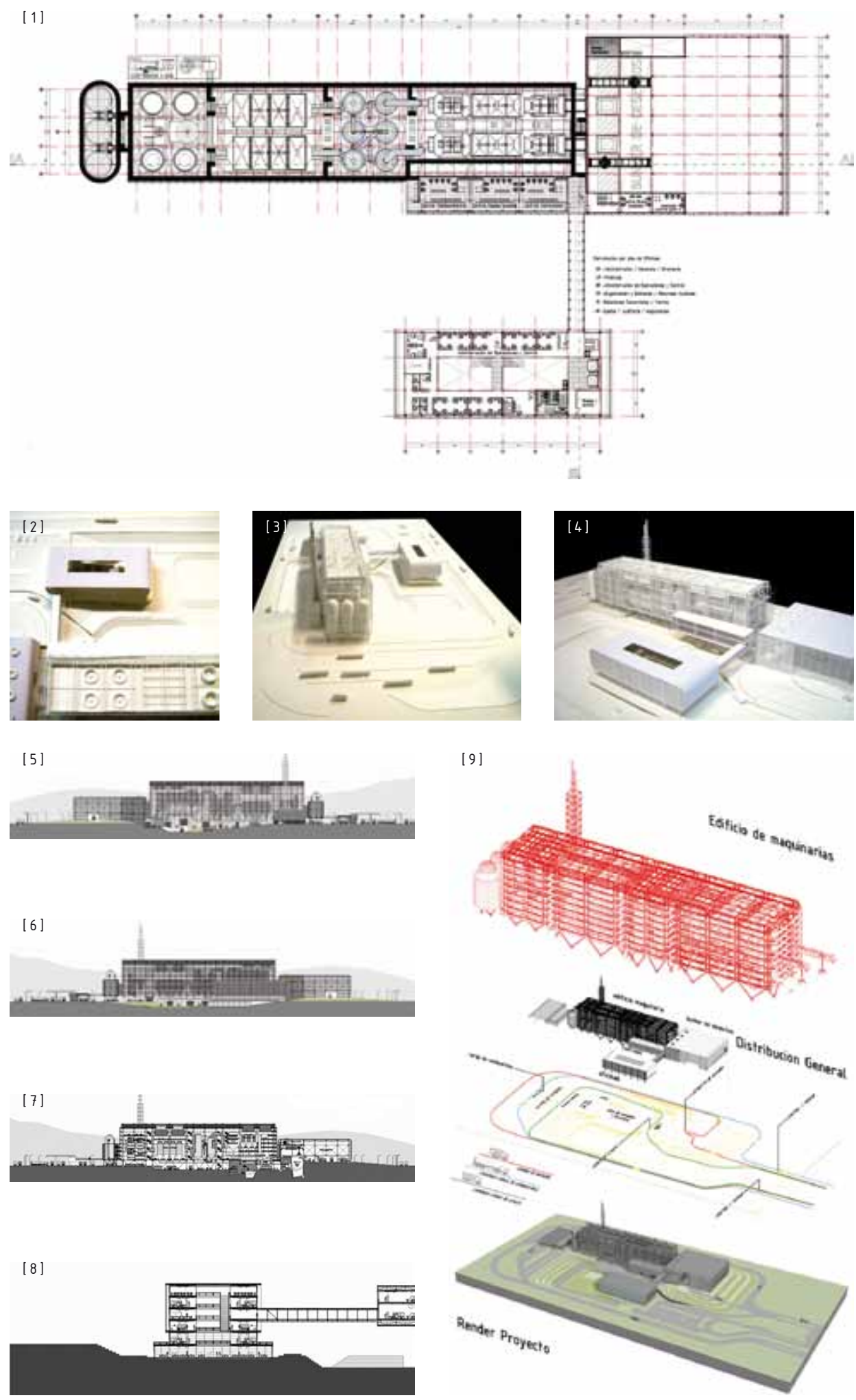
Estación Móvil de Ecoturismo e Investigación: Patagonia, Reserva Nacional Archipiélago de las Guaitecas / XI Región

Débora Santa María H. / Profesor guía: Juan Cárdenas S.

[1] Modelo. /

[2] Planimetría de la cubierta principal, /

[3] Planimetría de la segunda cubierta. /

[4] Corte longitudinal. I

5] Cortes transversales / [6] Escantillón. /

[7] Medio - Emplazamiento.

La Patagonia Occidental es un territorio escasamente asumido por nuestro país, sin embargo constituye una de las reservas naturales más importantes del mundo. Un extenso mar cobijado entre archipiélagos y fiordos, donde la tierra alberga un bosque siempreverde impenetrable y abrupto es el medio en el cual este proyecto se implanta. Atendiendo las necesidades de una región que ansía y camina hacia un desarrollo en las líneas de explotación y conservación se propone potenciar el Turismo de Intereses Especiales, específicamente el ecoturismo y la investigación, brindando infraestructura necesaria para su desarrollo y a la vez generando as instancias propicias al estudio y protección de este capital natural.

El proyecto plantea como primera premisa reconocer las características de este contexto físico a través de sus preexistencias. Éstas hablan de un territorio que hasta el día de hoy se ocupa principalmente a través del agua: ya sea por los Chonos en el pasado, como por la acuicultura en la actualidad mediante un sistema de producción íntegramente fundado en el mar. La segunda premisa es la alternativa programática que busca complementar el ecoturismo y la investigación en pro del estudio, reconocimiento y conservación. Alternativa que exige una necesidad de vincular el mar con la tierra.

La visión estratégica radica entonces en recoger ambas premisas, adjetivando la posibilidad inherente que tiene el habitar en el agua: la capacidad de itinerar. Este factor potencia aún más la propuesta programática, ya que permite ir conociendo y estudiando diversos parajes minimizando el impacto en el medio. Es así como se posibilita abarcar una extensión mayor de territorio en el tiempo y llegar a los lugares más remotos: ESTACIONAR, PERMANECER y servir de apoyo a las actividades de ecoturismo (información, instrucción y refugio) y de investigación científica (laboratorios, refugio, abastecimiento y medios para la investigación).

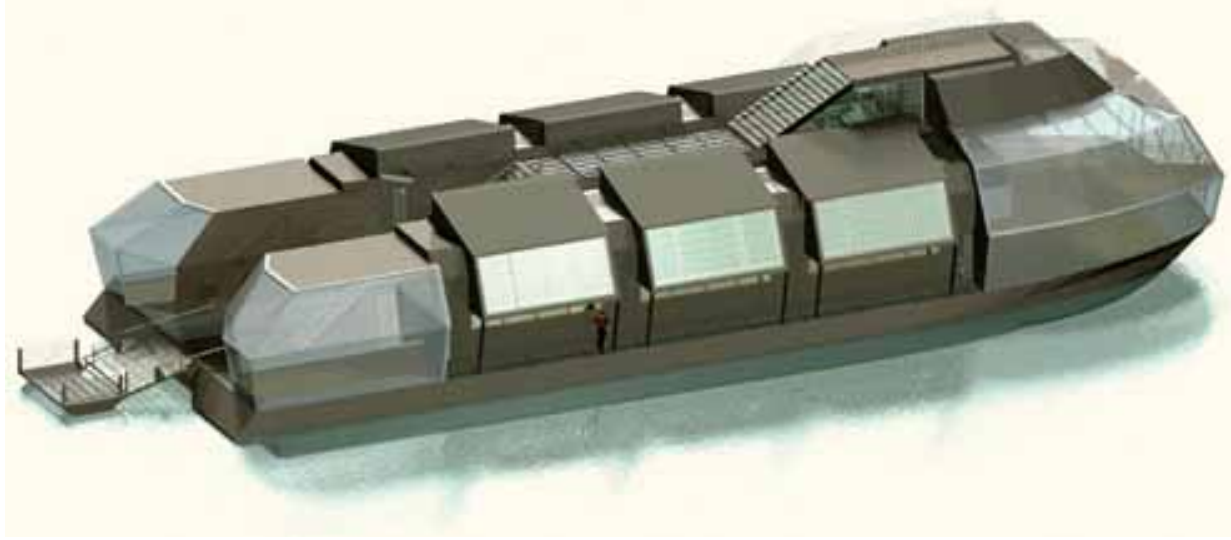

[2]

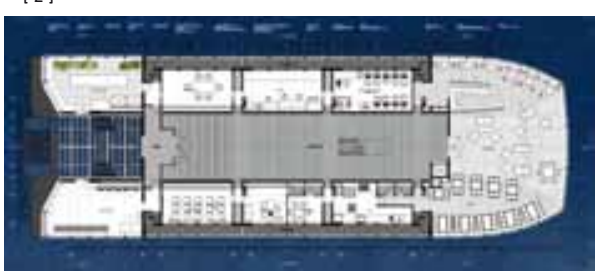

[4]

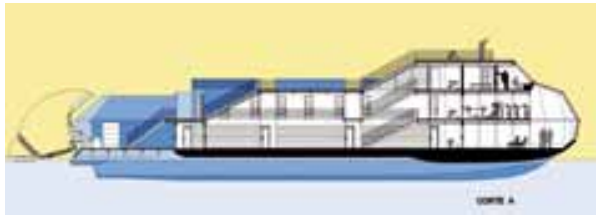

16

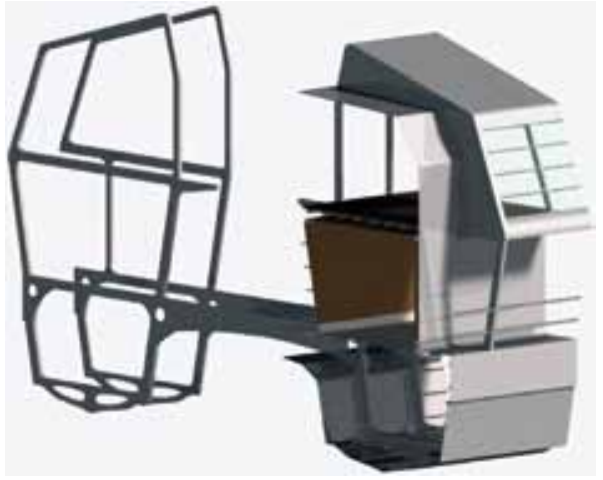

[3]

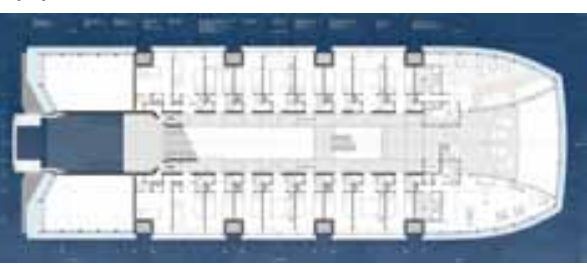

[5]

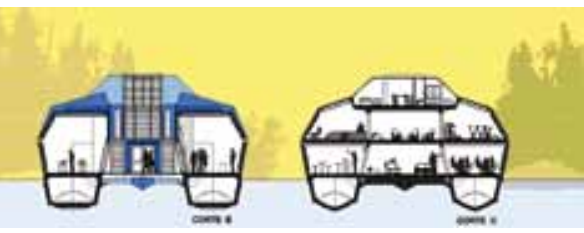

[7]

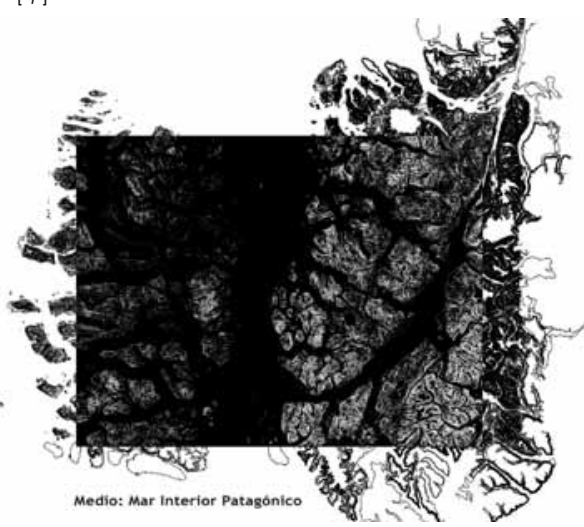


Museo de Arte Popular Americano / Valparaíso

María José Peña T. / Profesor guía: Alberto Montealegre K.

[1] Emplazamiento / [2] Terreno a

[3-5] Croquis del interior. /

[6] Corte escantillón. / [7] Fachada norte.

El proyecto de título fue abordado como un proceso en el cual debía buscar la coherencia de cada elemento en el resultado formal. Cada decisión de diseño debía ser honesta, correcta y coherente con el lenguaje que el proyecto utilizaba para comunicar de manera clara la materialización entre programa y contexto. Aprender el lenguaje establecido por el contexto y reinterpretarlo es la base desde la cual se comunica una idea y se relaciona. La arquitectura por tanto debe comunicar, debe decir algo.

Las tres problemáticas básicas que el proyecto buscó desarrollar fueron:

- ¿Cómo nace la forma?

- ¿Cómo adquiere carácter y significado?

- ¿Cómo la manipulo para que sea lenguaje?

Todas ellas desde la premisa de que el lenguaje arquitectónico trabaja con formas y es a través de ellas que debe expresarse. Por lo tanto la respuesta a cada problemática se manifiesta en el resultado formal del proyecto.

La forma nació de la lectura de un emplazamiento y programa especifico, la cual en su dialogo provocaron una resultante única.

El carácter y significado aparecen en la intervención del hombre, que en su "ser contemporáneo" confiere a la obra, de manera inherente a sus símbolos. Así como el lenguaje desde el cual puedo manipular la forma, es a través de la correcta y honesta utilización de la técnica.

El programa Museo de Arte Popular, permite poner en valor esta inquietud por el trabajo con el patrimonio actual. Reflexionar sobre los modos en que éste debe ser puesto en valor para mantener su vigencia como objeto y uso.

El objeto "popular" es la coherencia entre contexto y programa (uso), por lo que desde el objeto podemos establecer una metodología de trabajo para ser igualmente consecuentes.

Los modos en los cuales el proyecto dialoga se ven en el desarrollo y resultado formal final.
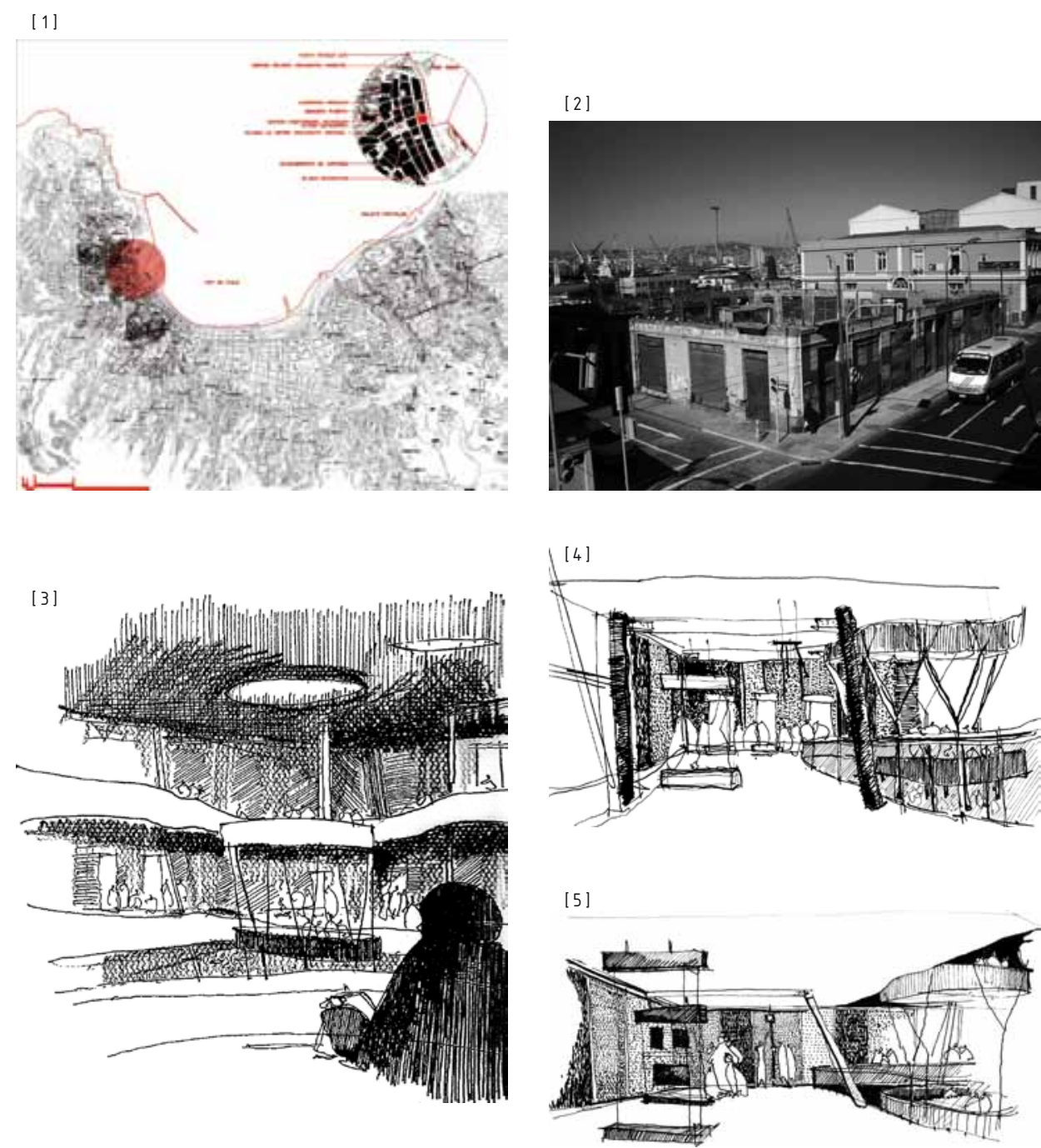

[6]
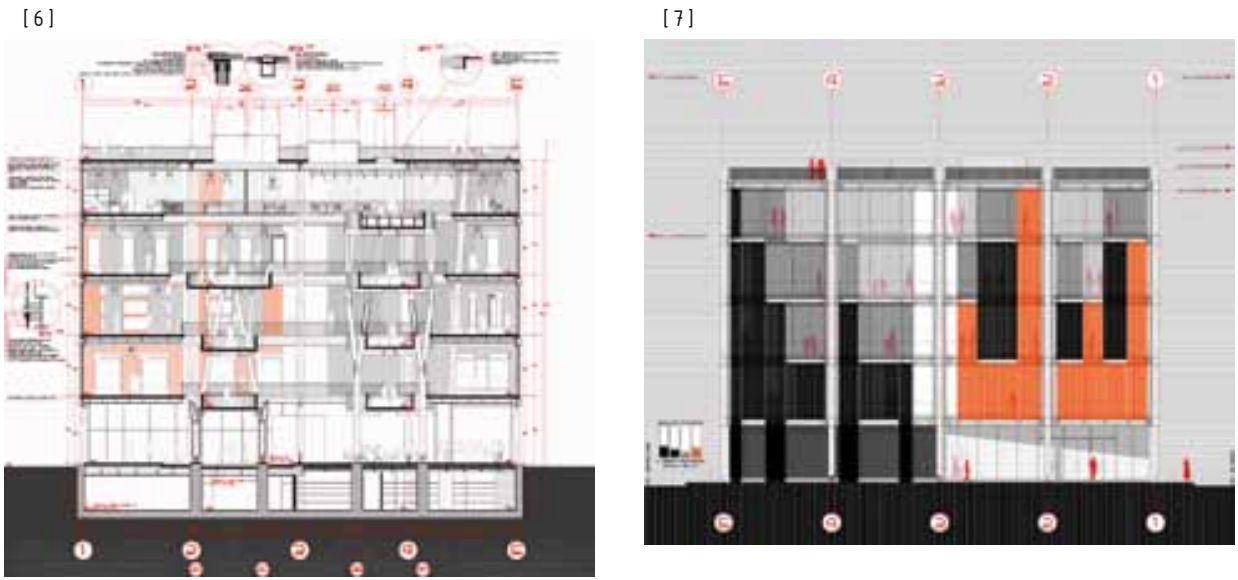
Museo Astronómico "Laipintur Muttu" (en idioma Kunza: Mirar hacia arriba) / San Pedro de Atacama

Marisol Blázquez C. / Profesor guía: Humberto Eliash D.

[1-2] Vistas del conjunto /

[3] Maqueta en corte.

[4-7] Vistas interiores. I

[8] Corte transuersal.

A partir de la necesidad de difusión de la astronomía, que nace de la implementación de observatorios en el norte de nuestro país, y principalmente de la futura creación del observatorio radioastronómico más grande del mundo, llamado ALMA; se plantea la creación de un Museo Astronómico que acoja esta necesidad.

Estará ubicado en San Pedro de Atacama, debido a su cercanía con estos observatorios y por ser uno de los centros turísticos más visitados de nuestro país.

Específicamente se ubicará en un terreno en la zona poniente, fuera del área urbana, lo que se debe principalmente a la conectividad con el centro y al alejamiento de la contaminación lumínica. Esta zona tiene un carácter distinto, que se refleja en un paisaje natural constituido por lomas que bordean el río San Pedro. El proyecto quiere ser parte de ese paisaje, y responde a esto desprendiendo su forma en planta de las cotas de nivel y en cuanto al techo lo hace adoptando formas sinuosas propias de las lomas.

La idea principal de este museo es enterrarse para direccionar la mirada al cielo. Siempre tenemos el cielo sobre nosotros, pero rara vez dirigimos la mirada. Por esto, el museo plantea la idea de ir dirigiendo la mirada gradualmente. En un primer nivel el museo se abstrae completamente del exterior, realizándose exposiciones diurnas principalmente mediante proyecciones. En un segundo nivel dirigimos la mirada en forma puntual al cielo mediante telescopios amateur y un planetario que durante el día funciona en forma artificial, pero que durante la noche se abre y funciona en forma natural. Finalmente, en un tercer nivel se plantea una terraza de observación para mirar libremente el cielo.

El interior del museo nace de su temática principal: el cosmos. Por lo tanto, se plantea de bordes indefinidos y con cuerpos aislados que están contenidos dentro de él. Así el visitante al recorrer el museo tiene la concepción espacial del cosmos.

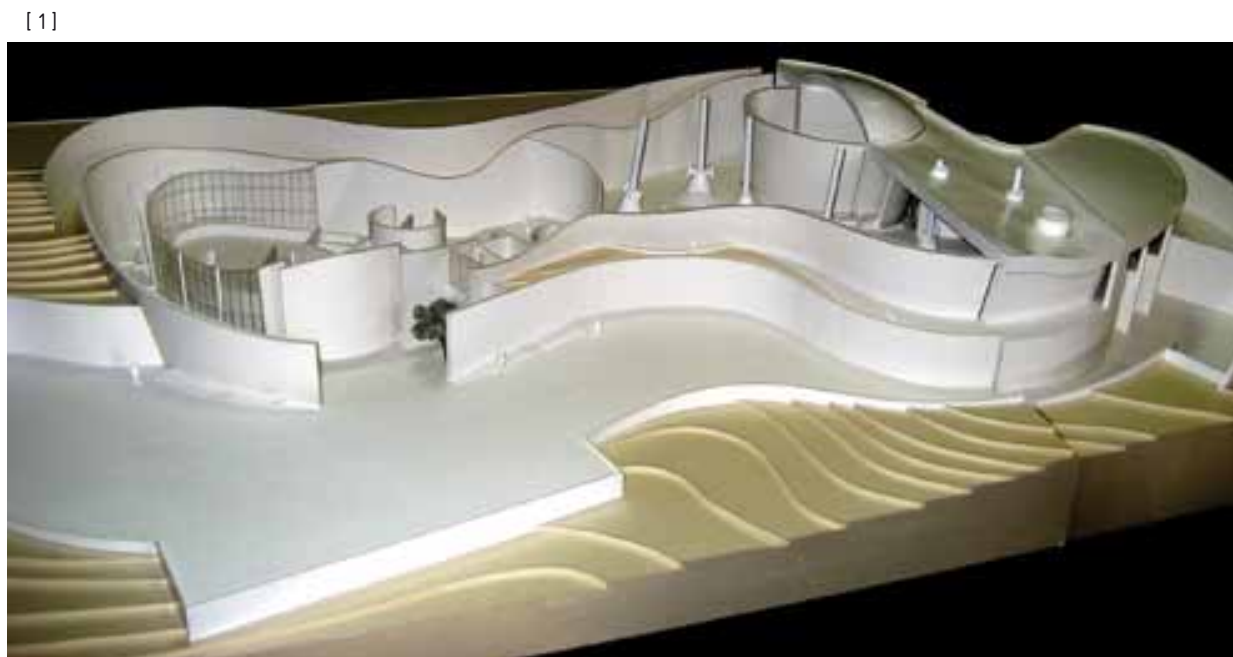

[2]

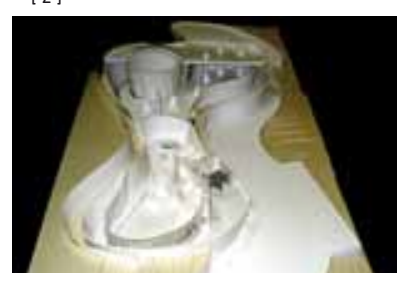

[5]

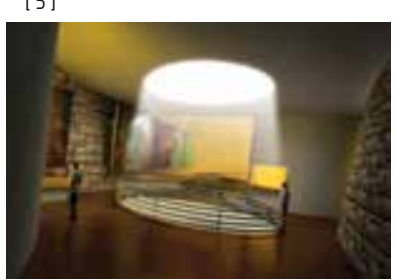

[3]

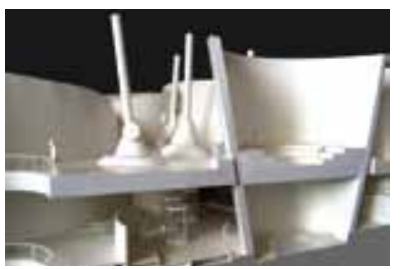

[6]

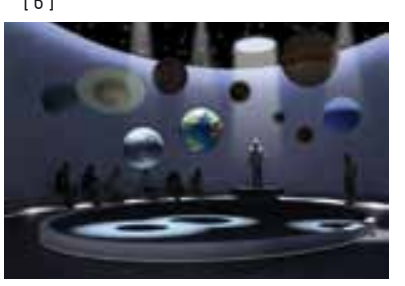

[4]

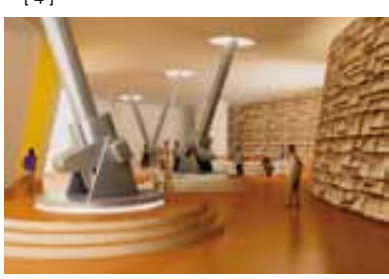

[7]

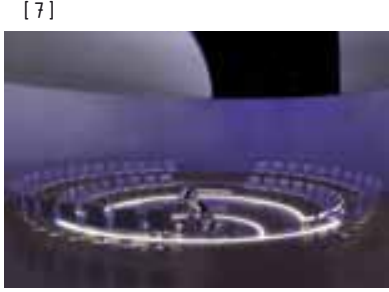

[8]

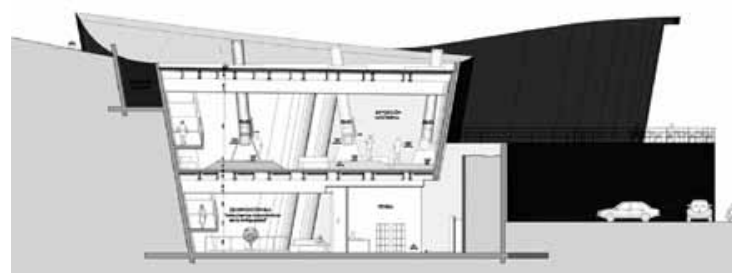


Ministerio del Medio Ambiente / Santiago

Mauricio Loyola V. / Profesor guía: Humberto Eliash D.

11] Corte / [2] Planta / [3-4] Vistas / [5] Estudio de superficies.

[6] Estudio de fachadas.

Este proyecto está ubicado en la intersección del Paseo Av. Bulnes con el Parque Almagro, dentro de la unidad espacial y simbólica del Barrio Cívico, pero en su extremo más distante, menos conformado y más verde. El terreno está afecto por una normativa extremadamente estricta que regula incluso elementos de composición de fachada como vanos, materiales y colores.

La forma general del proyecto resulta de considerar simultáneamente las exigencias de orientación contradictorias de cada dimensión del medioambiente: natural, construido, social. En el nivel superior se libera el norte para obtener ganancia solar directa, a nivel medio se conforma la arista sur para ser coherente con la morfología urbana y concluir el plan original de Karl Brunner y a nivel de suelo se libera la esquina para dar continuidad peatonal y permitir el cruce de vistas hacia el parque.

La fachada se obtiene del cruce entre 5 variables ambientales (calor, insolación, luz, brisa, vistas) y 4 acciones de respuesta sobre los vanos (agrandar, achicar, quitar, agregar). Cada variable fue estudiada por separado utilizando un software especial y se diseñó una fachada de respuesta para cada caso. La combinación de todos los diseños independientes origina la fachada final, que representa, por lo tanto, el diagrama construido de la optimización del comportamiento ambiental de la envolvente del edificio.

El edificio es un referente en el uso eficiente de la energía. El diseño utiliza fuentes pasivas (sol, brisa, energía geotérmica, Iluvia) en combinación con sistemas activos. Luego de una simulación computacional, el proyecto demostró ser el $42 \%$ más eficiente que el edificio vecino.

La planimetría, memoria completa y más imágenes de este proyecto se encuentran disponibles en www.superficie.cl/ministerio

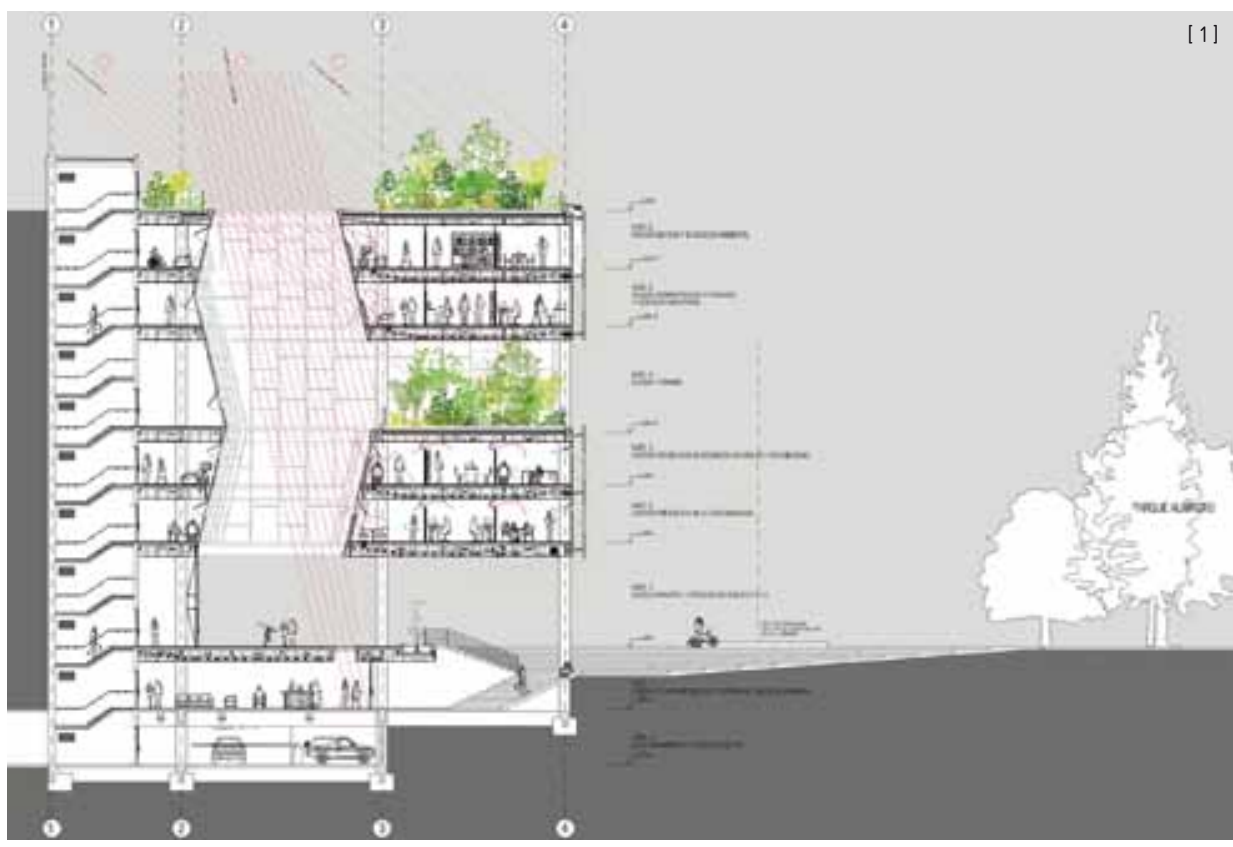

[2]
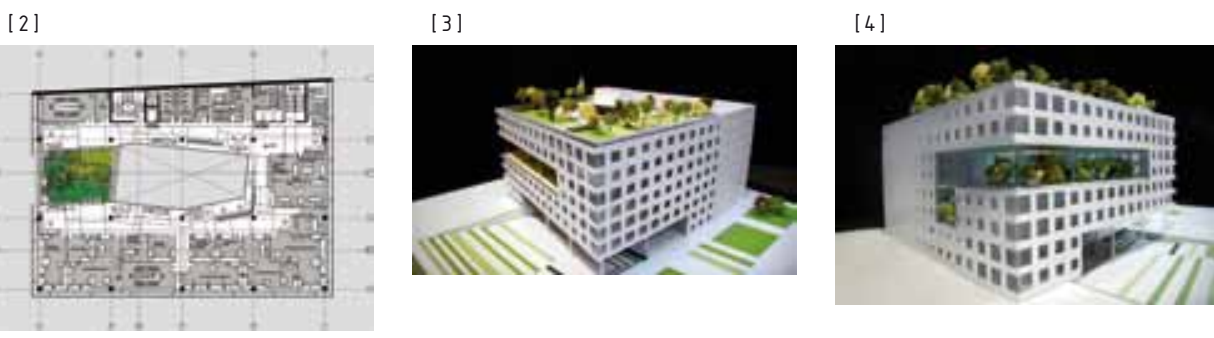

[5]
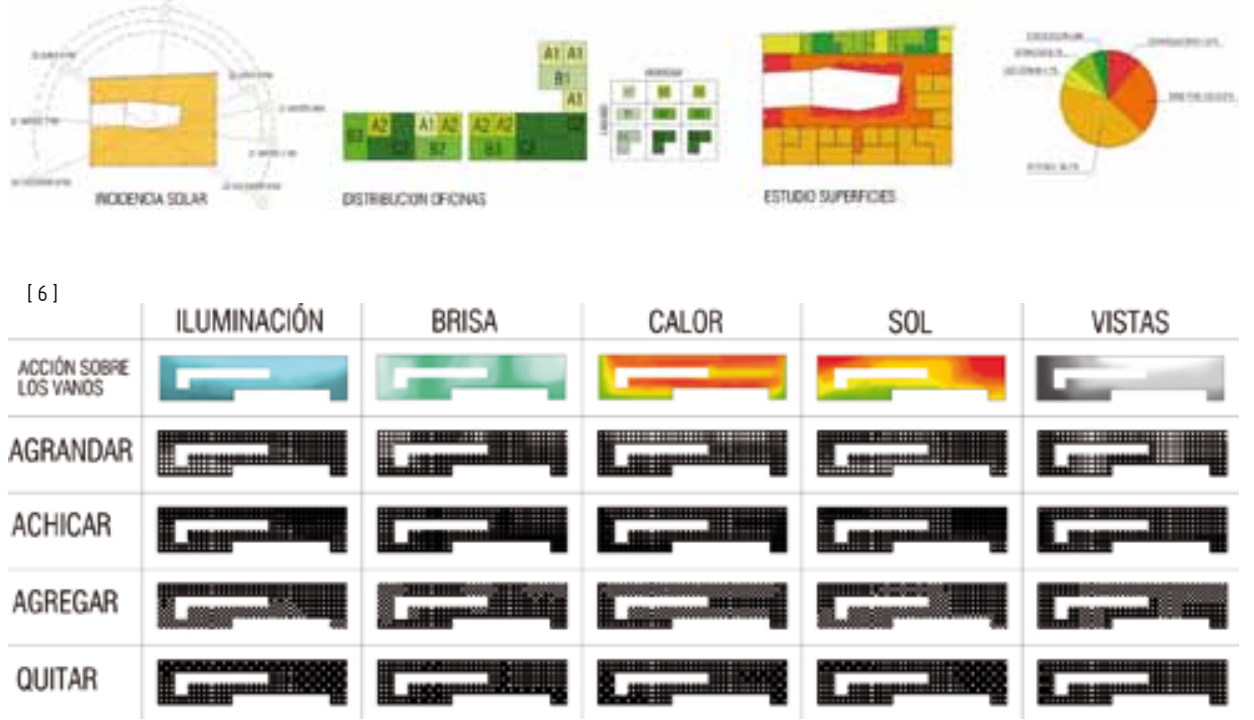
Soporte Turístico-Recreativo para Chuquicamata: El abandono como escenario de paisaje, memoria y productividad / Chuquicamata

Paulina Fernández L. / Profesor guía: Eduardo Lyon R.

[1] Planta del plan mastro. /

2] Maqueta del centro de visitantes.

[3] Vista del pabellón de acceso.

[4] Maqueta del pabellón de acceso. /

[5] Cortes de conjunto.

[6] Cortes del centro de visitantes.

El proyecto encuentra su causa en el interés personal por trabajar en las áreas devastadas de nuestro tiempo, aquellas que hace años Robert Smithson denominaba entrópicas, zonas abandonadas, condenadas al olvido que ya no son las mismas, al menos, en el territorio nacional. Lugares que aún están ahí, pero que sabemos que les queda poco tiempo, generando una destrucción irracional de un patrimonio sin alternativas de futuro.

El caso del campamento minero de Chuquicamata, que hoy se halla ante su inminente desalojo y desaparición del sector habitacional es un ejemplo.

Sin embargo, cabe pensar que hay un proyecto posible, que los campamentos mineros, pueden rescatarse de la memoria ciega y transformarse en paisajes visitables, visibles y de la memoria, campos ligados al tiempo y a la cultura, pero también a un conocimiento de esa otra cultura, la del paisaje culturizado $=$ cultivado

La idea de pensar los campamentos mineros como una red dotada de entidad se aparece como algo más que un proyecto posible; se aparece como un proyecto que es necesario de imaginar y construir para dar verosimilitud al futuro paisaje chileno, un proyecto con la idea de ligar paisaje, memoria y productividad.

El problema que se plantea abarca por una parte las formas de gestión del turismo en antiguos campamentos mineros, y por otra parte el tema de la conservación del patrimonio cultural tangible e intangible.

Frente a esto, el proyecto busca la mantención y recuperación de los aspectos positivos de la "identidad" y la "memoria colectiva" de Chuquicamata y conservar estructuras del campamento de Chuquicamata, que representa parte importante del patrimonio minero de ésta, logrando un diálogo entre ella, su muestra, la ciudad, los habitantes y los visitantes y así, proponer un proyecto con el fin de fortalecer el rol turístico, en la búsqueda de diversificar las actividades de la zona, en pro de incentivar la economía, entregando una fuente de trabajo e ingresos para la comuna.
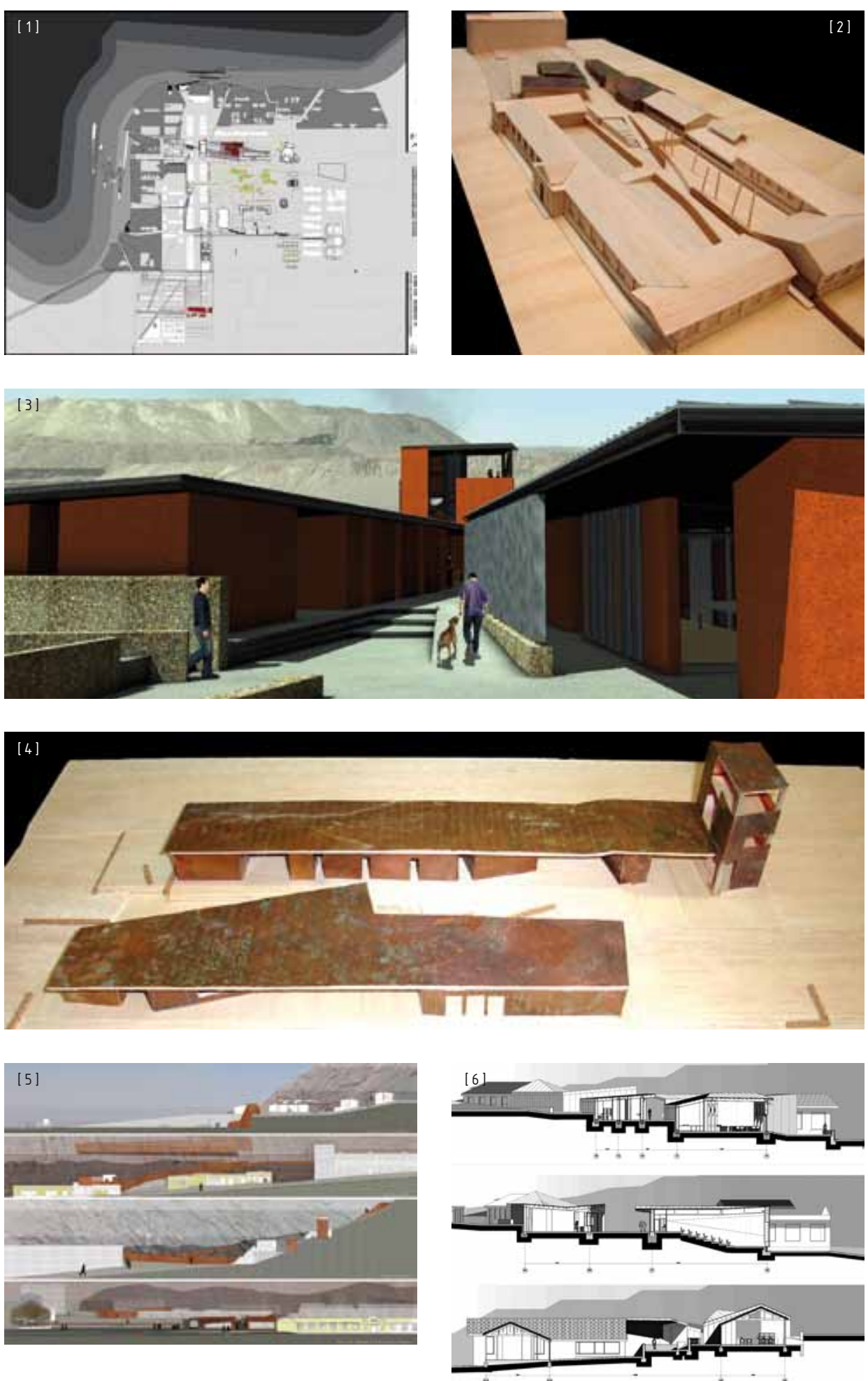